\title{
Application of Blended Learning through Practical Project-Based Instruction: Opportunities and Constraints
}

\author{
Rahman Tafahomi ${ }^{1}$ \\ ${ }^{1}$ Department of Architecture, School of Architecture and Built Environment, College of Science and \\ Technology, the University of Rwanda \\ e-mail: tafahomi@gmail.com
}

\begin{abstract}
The aim of this paper is to highlight the application of BL (Blended Learning) in practical courses in the architecture program in COVID-19 time. Physical Environment course is a theoretical module in the first year of the undergraduate architecture program. Despite the course write in the theoretical structure, it was proposed to reorient the course into mixed methods with practical activities through online researching, site visiting, and reporting. The methodology was designed in a qualitative method with the application of case study, structured observation, content analysis, graphical analysis, and interpretation techniques. Data were combined from 40 students who were divided into 10 groups of 4 students to discover the application of BL in a practical and project-based activity. The findings of the research identified that the students face limitation to access the research engines and scientific sources to collect the sources for exercises. A half part of the group did plagiarism in the citation and referencing of the reports. The students present more accurate data in the site visiting and practical activities than the theoretical part. In conclusion, the application of $\mathrm{BL}$ requires sufficient infrastructure for access to online materials through institutions. Application of practical BL helps the students to personalize and specialize the learning process through their own design of the report and exercises that more effective for delivery of course. Despite the BL implements just in the activity and course levels by staff and students, BL mode requires to set up in both program and institutional levels to achieve the results.
\end{abstract}

Keywords: blended learning; architecture; practical; project-based; teamwork

How to cite : Tafahomi, R. (2021). Application of Blended Learning through Practical Project-based Instruction: Opportunities and Constraints. Pedagogi: Jurnal Ilmu Pendidikan, 21(2), 77-89. https://doi.org/https://doi.org/10.24036/pedagogi.v21i2.1093

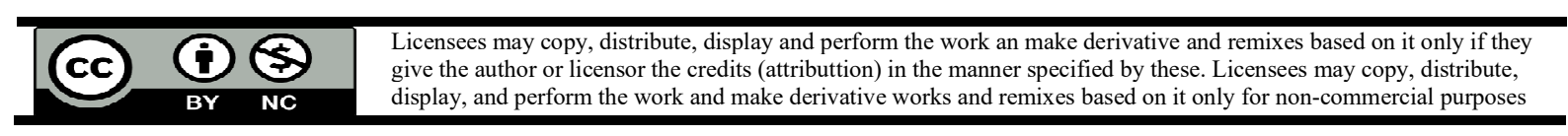

\section{INTRODUCTION}

There is a wide range of discussion on blended learning (BL), particularly in higher education. Despite the background of BL in terms of a mode of education, the common perception refers to a mixture method of teaching with online (digitized method) and on-campus (traditional method) activities (L. C. Medina, 2018). The study highlights that the major part of the universities oriented toward the BL (Allen et al., 2011). BL called in terms of the future of universities in the near time (Gibson et al., 2016) although the study revealed that a major part of the departments and instructors less adapted to the online teaching mode and preferred to continue on-campus activities (Graham \& Robison, 2007). The COVID-19 condition accelerated the process to shift the physical classroom to the online activities in some universities with an account 
on the internet capacity to serve the courses (Garrison \& Kanuka, 2004; Powell, 2011) although it was supposed that the content and syllabus should keep the same. In this context, it was supposed that lecturers design their own modules for online teaching as a general perception about blended learning.

Some of the universities are struggling with the paradigm-shifting from the physical classes to a BL structure due to the many issues such as the infrastructure, staff, and the experience. The problem takes the position in the department when they assume that blended learning is just online teaching than flexible schedules. This problem is highlighted in the practical classes, studios, and workshops that are common in architecture departments due to the structure of teaching in terms of apprenticeship activities (Schon, 1984; Shulman, 2005). An undergraduate architecture program includes both theoretical and practical courses, which takes the place in the studio. With the shifting from physical classes to the online courses and the BL structure, seemingly, some gaps happen in the absence of sufficient level of training, experience, and facilities.

COVID-19 circumstance resulted in lockdowns of the country for two major times that affected the educational institutions including the department of architecture at the University of Rwanda. It was supposed that departments and instructors start to shift the activities from traditional mode as face to face to BL mode to support the general policy of the university in terms of protection of cases through social distance and online learning. The department includes around 130 students and 8 staff that each instructor presents three courses in each semester. However, the architecture program was designed based on the practical activities of the students based on engagement approach of the students in the practical activities such as drawing, physical model making and design process based on the idea that doing and repeating the activities is the best way for the learning of the knowledge and skills. Nonetheless, shifting from traditional mode to $\mathrm{BL}$ is the current challenge that the department and instructors face dealing with through actions.

The architecture curriculum includes groups of modules such as theory, history, technology, science, visual, and design studio. Nonetheless, it is supposed that all courses support the design studios with different thematic topics. One of course in the first year of study is Physical Environment to introduce the students to the physical elements in the environment that influence the design process, elements, and typology. The physical environment includes both theoretical presentation and site visiting to make the students familiar to the elements. It is common to apply PowerPoints for presentation, books and journal to share the contents, webpage to refer to them and educational movies for the visualization the physical environment in the classroom. However, the COVID-19 condition shifted the university from a normal classroom to blended learning mode with online and physical classes in the department. Despite the university was in a rush to implement the BL at certain levels, the achievement to the target was dependent on the staff in the activity in the classroom and the content of the course than the program and institution (Graham, 2009).

It was a great proposal to assume a combination of the online and offline studies with flexibility in times and activities based on a teamwork of the students in the course delivery process and stages. To hypnotize this assumption, this research is planned to integrate the projectbased activities with emphasis on the survey and documentation activities to arrange a process of the self-activity, self-learning, and self-planning of the learning process in a blended learning process (Medina, 2010; Palmer \& Holt, 2014).

According to the studies BL mentioned as a mixture of online and classroom education. The questions of this research are included some topics to ask how could BL mode support the practical activities of the students in the architecture course? Do practical activities such as site visiting could support the learning process of the students through a mixture of online and on land exercises? Does teamwork activities support the learning process of the students? How the flexibility of BL supports the learning process to personalize and specialize the learning in groups of students? 


\section{Discourse on the Blended Learning Mode}

Despite the current view, blended learning exposes a hybrid view of the online and oncampus learning structure that refers to a mixed approach for the e-learning and classroom learning (De George Walker \& Keeffe, 2010) based on the theory courses and technology availabilities (McGee \& Reis, 2012), there are three discourses on blended learning in terms of instruction, method, and modality (Medina, 2018). The instruction was defined by studies as a mixture of online and physical activities in the classrooms (Delialioglu \& Yildirim, 2007; Gülbahar \& Madran, 2009). This approach focused on the form of the class delivery and the administrative aspects of the teaching in the new approach. This relation between the normal classroom and the online activities recommend switching between the online and on-ground activities in the BL model of learning (Muñoz-Cristóbal et al., 2012). The BL also was discussed as a method for the teaching and platform in terms of technology and online activities (Rossett, 2002). The technological aspect of the BL emphasized in this approach. This combination of methods of teaching was mentioned by the study as an advantage of BL in classrooms (Gomez \& Duart, 2011). The study mentioned modality in terms of flexibility in time, contents and individual. For example, the study mentioned that the system of the BL should be flexible and customizable (Owston et al., 2013).

In another approach, Graham proposed a scaled BL in four levels including activity, course, program, and institutional (Graham, 2009). According to this classification, the activity referred to the online and on campus activities of the students. However, the course BL referred to the proportion of the online and on compose materials, time, and learning outputs that are structured in one module with a specific topic and purpose to lead both instructor and the students. The program BL referred to the structure of the program that how it fitted to the BL learning mode through different modes of learning including both online, offline, and on-campus. The institutional level as the most lager scale of BL explained the capacity of the institution to deliver the programs through BL based on the infrastructure, human resource, and digital technology. Seemingly, the first step in the application of BL was started from microscale in the activity level than institutional.

The study revealed the benefits of blended learning in higher education. For example, the study listed three benefits with the BL in higher education including flexibility of the times management, cost reductions and the variety of online sources (Medina, 2018). Another added the flexibility of educational content for individual students in the process of implementation BL model of learning (Owston et al., 2013). For example, Chen and Jones mentioned benefits of switching the time and spaces for the training of the students that included positive effects on the learning process (Chen \& Jones, 2007). The study revealed that the students learnt more in BL than in traditional classes (Aycock et al., 2002). For example, the study mentioned that BL supported the students in the decision making in the process of learning (Moore \& Gilmartin, 2010).

The teamwork in the BL model emphasized by studies (Prieto et al., 2012) to enhance the level of the socialization of the students (Dziuban et al., 2004). The studies stressed the enhancement of the relationships between learners, classmates, and the instructor as the key aspect of BL (Hewitt, 2003; Sutton, 2001). The studies exposed a personalization process by students in BL to apply knowledge, skills, and ability in the learning process in both theoretical and practical aspects (Williams \& Robert, 1997; Woolfolk, 2016; Woollard, 2010) that are resulted in selfplanning and self-organization attitudes (Medina, 2010; Palmer \& Holt, 2014) that are supposed to engage the students in some practical activities (Medina, 2018).

Some key elements were emphasized by the studies including flexibility of times, criteria for evaluation, and proportion between the online and on-campus activities. The flexibility of the times in the teaching and learning process is the key factor in BL (Picciano, 2009; Piper, 2010)that cited widely in terms of the synchronous and asynchronous plan for BL. The study mentioned that 
blended learning is dependent on the educational environment and different contexts to design different methods in BL. The studies recommended the clarification of the adaptable modules with the blended learning in each program due to some difficulties to shift all modules into BL (Martin, 2003). Also, the studies advocated that the BL needs certain levels of education and training to use by the instructors.

Lane et al. criticized that the style of education in architecture did not change profoundly from a handed year ago based on project-based activities and apprenticeship (Lane et al., 2015). The studies emphasized the personal attitude of the instructors to design the instructions to follow their own tradition of the teaching style in architecture education that (Schon, 1984) mentioned as a personal signature and (Lawson, 2005) described in terms of a prescriptive approach to design activities in architectural courses. This challenge between the academic and professional labels in the architecture (Lane et al., 2015; Shulman, 2005) resulted in to degrade the level of the research and theoretical activities in the program. Therefore, the project-based outputs as the practical activities have taken into account as an important priority in architecture education.

In summary, there are some aspects that are significant in BL in the architecture courses including the theoretical aspects, educational materials, practical activities, and deliverables products by the students. The theoretical aspects encompass the studies that the students do through the educational materials such as books, journals, movies, and other online source are available for the study. The practical activities of the students are the undertakings a project-based actions by the students to assimilate the knowledge and improve the skills through doing such ad drawing, survey, research, and site analysis. The output of the activities and studies are presented by the students in the format of the report, redrawing, and design products. Therefore, the process of the lessons learnt by the students is expected to represent through the deliverable of the learning outputs to demonstrate the effectiveness of the BL in the activities.

\section{METHODS AND MATERIALS}

The methods and material part were included methodology, research design, research process, data specifications, and time and location of the research.

\section{Methodology}

The methodology in education has been included both quantitative in terms of positivism approach and qualitative as an interpretative paradigm (Cohen et al., 2017; O' Sullivan, 2006) to study teaching and learning process such as blended learning. The studies recommended qualitative methods to study the problem in the context for a profound analysis (Groat \& Wang, 2002; Silverman, 2004). The applied techniques in qualitative research in education were included content analysis (Krippendorff, 2003; Mugerauer, 1995), case study (Graham et al., 2013; Medina, 2018), interview (Cohen et al., 2017; Neuman, 2006), structured observation (Bonnes \& Bonaiuto, 2002; Tafahomi, 2021b), and behavioral analysis to study the activities in the context (Tafahomi, 2020, 2021a; Tafahomi \& Nadi, 2020). The quantitative research constructed on the questionnaire with a wide range of data for the statistical analysis of big data through software (Cohen et al., 2017; Hemyari et al., 2013). For example, (Medina, 2018) applied the questionnaire to check the opinions of staff and survey to discover infrastructure facilities in the university.

\section{Methods and Research Design}

The applied methods in this research were referred to the legitimated process that presents the research activities in data collection, analysis, and interpretation of the results. The content analysis (Krippendorff, 2003) and the structured observation (Bonnes \& Bonaiuto, 2002; Tafahomi, 2020, 2021a; Tafahomi \& Nadi, 2020) applied to analyze the activities of the students in blended learning in the architecture program. The content analysis was applied to analyze the products of the students in the exercises specifically based on the structure, content, and the graphical presentation of the students especially the quality of the online sources, citation, and the references in the report structure as the key criteria. The reports of the projects that the students 
provided based on the exercises were analyzed based on both quantity and quality of the research online sources, graphical features such as photographs and sketches, and structure and results.

The structured observation was applied to check the behavioral patterns of the students in the groups in term of the teamwork activities in the project-based activities, plagiarism, and supportive attitudes. The project-based activities were referred to the site visiting of the students to observe physically and actively the physical elements in the site to report their own understanding of the physical environment in the format of the report. The progress of the students in the teamwork, collecting data through both photography and sketching in the sites were the main key criteria as the structured observation. The level of plagiarism in the reports of the students also referred to the level of the research, citation, paraphrasing, and referencing. The students made groups in the teamwork that supposed to support the students in the activities. The level of collaboration or competition between the students in groups and with groups observed systematically to discover the level of collaboration in the teamwork activity.

\section{Research process}

To start the Physical Environment module in BL, the instructor applied three types of online sources to introduce the students to the teaching system including UR Moodle, Dropbox, and Turnitin. The UR Moodle was the official website that it was supposed all the material add to the course page gradually. Therefore, the course page encompassed different topics including topography, light, temperature, rain, water system and water collection, geology and stones, soils, and manmade elements importantly buildings. It was supposed the students register in the Moodle and use the materials. However, there was disconnections with the system that need to the other supportive platform. For this reason, Dropbox was introduced as data back to the students to download and upload the materials and exercises in the dropbox. The Turnitin was an official website by the account of the university to check the level of plagiarism in the students' deliverables.

To do the research, BL designed based on the eight exercises to check the level of the effectiveness of the BL in the course. To achieve the target, the exercises were included specific topics based on the presented lectures in the classroom. To increase the level of the effectiveness of the topics and course, the exercises were designed to encourage the students to do research online, to visit sites, to documents the observations through photographs and sketches, and report all activities in the format of the exercise in the groups of students including 10 groups of 4 students totally 40 students.

The instructor provided a handout to lead the students in the on-ground activities. The structure of the handout encompassed the starting time and ending time of the exercises and the periods of the activity, a summary of the topic, the learning objective of the topic, the task of the students, deliverables that should be produced by the students, marks allocation for each activity, and list of the criteria for the marking. The students had the right to access all materials in both dropbox and Moodle to download and apply in the research, citation, and references.

The instructor reviewed the reports of the students and commented on them individually. Also, all the works checked by the Turnitin site. Then the project marked and the grades shared through dropbox. The students had the right to see projects of other groups of students, comments, and level of plagiarism. Despite the low level of privacy in this process but it was supposed that the student could learn through this accessibility to all deliverables, results, and comments to improve the projects.

\section{Data specification}

Data of the research was combined from 40 students (35 males and 5 females) in the first year of study in the undergraduate program in the department of architecture. Data of the research was collected through produced materials by the students in the different exercises importantly the online sources, citation and referencing from online sources, the level of plagiarism, photography 
from sites, and drawing of physical elements and redrawing of the published sources, the structure of the reports, and teamwork activities. The students provided through sources, arranged in the reports, and submitted for the evaluation and marking. Data were combined from text and graphical data to be evaluated through the descriptive approach.

\section{Time and location}

The research took the place in the second semester of 2019-2020 between two important lockdown periods. The class activities were included two types importantly, online teaching through Microsoft meeting software and explaining the practical activities in the real site for the observation and analysis. The selected site located in Kigali city as the context of the study where the students living and studying. The students had the right to select their own site based on the availability of the physical environment features. The site located in the valleys and hills of Kigali in which the students found some examples to document and report.

\section{Research Limitation and Implication}

The research took the place in COVID-19 times and between two major lockdowns in the city with restriction of the traveling and accessibility to different parts of the country. Therefore, the research was designed in the limitation of the sites and survey activities. The students had limited time to visit and document the sites and return back to the home and this affected observation and survey operation in the research process. The restriction also affected the site selection based on accessibility, distance, visiting permission, and time management.

\section{RESULTS}

The exercise was included 8 CATs (Continuous Assessment Testing System), which was designed based on the reporting on the physical activities including searching, reading, referencing, citation, site visiting, data collection, documentation, and reporting.

\section{Searching and Reading Open Sources}

Despite the handouts of the exercises, a major part of the group of students started with a low number of online sources. They preferred to use webpages and weblogs as an authentic souse. Although the research engines introduced in the classroom, the groups of the students used more the webpages. The number of books, journals, and conferences did not observe in the categories of the researches. This style of the research included both scientific and personalized point of view of the authors on the weblog that the students referred to.

\section{References and Citation}

The students preferred to add the list of references at the end of the reports based on similarity to the title of the webpage and the exercise such as light direction, and wind speed or application of stone in housing construction. Nonetheless, the level of the application of the reference improved gradually based on a continuous comparison between the report of the other groups, marks, and comments of the instructor. This process resulted in increasing in the level of the searching, discovering, reading, and application of online sources in the research report.

The citation was a difficult task for the group of students. The level of citation of the online sources in the report was so low. Despite the handout illustrated the citation process in the structuring the report, the groups of the students assumed that mentioning the list of references at the end was sufficient to represent the study, research, and reading process. Just two groups of students succeeded to improve the citation and other groups focused less on the citation in the report.

\section{The level of Plagiarism}

A half parts of the students plagiarized in the earlier stage of the exercises. Turnitin site illustrated that the students applied webpage contents for plagiarism than books and journal 
papers. This attitude demonstrated that the students trusted on the first source in the internet to apply in the exercise activities than a comparison, analysis, and selection. Despite the award of 0 for plagiarism in the regulation of the University, the instructor allowed that students to repeat the exercise to clean the plagiarized sections. The report of the plagiarism was passed to the classroom and the students had the chance to see reports about their own group and other students. This comparison resulted in changing the member of the groups based on self-selection. The students were aware that who is interested in plagiarisms. The students avoided being grouped with the student who was interested in plagiarism due to the consequence on the marking process. This process resulted in reducing the level of plagiarism in the process of the course and exercises.

\section{Site Visiting}

For the site visiting and physical activities, the students presented different attitudes. The exercises of light direction and wind speed related to the general specification of buildings, the students applied their own house, building, and dormitory. The students documented the specification of the buildings and the physical environment freely at different times. However, for other activities that needed to visit other locations for documentation of the physical environment aspects the quality of the site visiting, documentation, and reporting were reduced such as collection water, riverside construction, and application of the stone in the buildings. Some groups of students attempted to apply photographs from online sources and represent some online reports as their own site visiting activities that the submitted report return back to the group for correction. Importantly, the students preferred to visit the locations close to the living areas than a wide investigation for the proper case to document and report.

\section{Photography and Sketching}

Despite the course present at the same time with the Visual Study II that the students learn photography, sketching, and presentation, the quality of both photography and sketching in the reports of the exercise were so low. The students used their own cellphone for the photography. The photographs were not accurate, detailed, and informative. The photographs in some exercise such as light direction and shadows on the building were informative. However, the general quality of the photography was low. The level of pixels of the photos was less effective on the quality of photos. However, other quality such as direction, frame, and composition of the photographs could less support the process of the documentation of the site visiting. Nonetheless, due to the comments of the instructor on the reports, and reading reports of other groups, and comparison of the marks achievements by other groups, the students learnt how to take more effective photos for the next exercise.

The sketching of the site visiting was not adapted to the architectural graphical standards. The students presented some rush 3D sketching that lines and drawing were so poor. They used fewer plans, sections, and elevations to represent their own observations. The sketches included less detailed aspects and proportions were not on the right scale. Despite the instructor shared two books with topics of architectural and environmental drawing, the resultant of the books less appeared in the drawing of the students.

\section{Reporting Structure}

Despite the structure of the report for the exercise recommended through the handout, the student preferred to follow and draw their own style of documenting and reporting the exercise. Although it was supposed that the students select a specific style and format to do the exercise as an innovation, it was requested that the students present the minimum information based on the handout of the exercise. Some of the groups used the recommended format and followed the structure for reporting the activities. The structure of the report was depended on the materials that the students collected, provided, and documented. Therefore, if the students could less collect the information through online research, site visiting, and documentation, therefore, the structure of 
the report was less effective due to the structure and the content. Nonetheless, the groups of students progressed through the exercise to respect the structure of the report and the minimum quality of the reporting.

\section{Teamwork Activities}

The teamwork activity of the students was high and effective in the whole process of the course and exercise. Despite the students had the problem with plagiarism in some groups, the students attempted to improve the problem through regrouping. The students did not claim about the members or duties in the groups. Seemingly, the assigned works in the groups resulted in cooperation, collaboration, and common understating of the duties. Some of the groups harvested fewer marks in the earlier exercises that it resulted in to request for more chance to the groups by other groups. This attitude highlighted that the level of collaboration and support system attitude were higher than competition sense between the students. The students three times changed the groups' composition; however, in each set of grouping the level of progress of the students was more effective. This fact highlighted that the teamwork activity supported the students in the learning process in the course through exercises.

The findings of the research identified some of the key aspects in the exercise including effects of the project-based exercise, learning through groups, learning through comments of the instructor, and the missing aspect in the structure of education in the department.

\section{Practical Project Activities in BL}

Adding the practical project-based activity leads the students to the more practical, physical, and experimental similar to an open laboratory to test the lessons learnt. Despite the BL is supposed to integrate online and physical activities as a model of learning, doing some practical research project in terms of live projects could increase the level of the understanding of the science and skills between the students. The exercise designed based on small practical projects for observation, measurement, and reporting by the student. This process of the activities designed sets of activities in the physical environment elements that are supposed the students learn.

However, the findings of the research demonstrate that the students are more effective in small projects with a clear boundary to documents and analysis than a bigger project. For example, the students presented the exercise of the light direction, temperature, and wind speed in their own house or hostel. The students' documentation and reporting in the wider area and site need clear boundary and benchmark for the activities. The students were free in the exercises to select the site for the analysis, reporting and documentation. Nonetheless, seemingly, they need more guidance for the sufficient process of the production than a self-learnt process.

\section{Learning through Material of the Instructor}

Despite the online materials and sources is recommended by the literature as an effective part of BL in the education process, the exercises identify that the recommended, shared, and provided sources are more applicable by the students in the process of learning in BL. In fact, the online sources apply by the students based on the time and budget for airtime consumption. However, the shared sources are assumed as the authentic reference to apply in the research, also there are free without the cost of the downloading and internet budget. Particularly, in the educational center with poor online sources, the provided materials have effective role to lead the students in the research process in BL although this approach limits the students to use just from provided sources without curiosity to explore other sources of knowledge.

\section{Learning from group members}

Teamwork activities in the exercises lead the students to share their knowledge and findings with other students. This process creates both competition and collaboration between the students and groups that in this research the level of collaboration and support system were more than the competition. The students support other members of the group in a different part of the exercises 
in a process of assigned activities. Although the instructor did not participate in the assigned jobs of the students, the resultants of the deliverables by the students highlight an effective and hidden support system between the students for accomplishing the tasks. For example, the students with the plagiarism experience were so attentive for doing plagiarism in the new group. This level of peer learning also observed in the photography and sketches that the members with the effective graphical techniques shared the knowledge and skills with the rest of the groups and enhanced the learning process of the members.

\section{Learning from other groups}

Not only the students learn from their own groups but also they are interested in the other groups' results, techniques, and structure. The students learn through both positive and negative experience of the other students. In detail, the students read the comments of the instructor not only for their own activities but also they read the comments for other groups to discover the weaknesses and strengths of the other groups to learn how to apply. This process creates a clear competition sense between the groups to push the members to enhance the quality of the deliverables for the exercises. As a concrete example, the structure of the report for the exercises varied due to the components and materials. However, the students learnt how to improve the quality of the report through reviewing the more successful report in the comments and marks. This process highlights that the students learn through the works of other groups.

\section{Problem of other courses in the department}

The structure of the fundamental and supportive courses are not effective in the department that is resulted in the weakness and struggle of the students to tackles the problem of those institutional problems. The students are supposed to pass two courses in visual studies that include drawing, sketching, photography, and presentation. However, the quality of the presentation of the report reveals the big gap in the knowledge and the skills of the students. Despite the online learning due to the COVID-19 condition in the country resulted in the less practical activities in the design studios, the gap in the skills of the students demonstrate the insufficiency of the courses for distance learning, online learning and BL. In addition, supportive courses such as ICT skills are less effective to improve the level of the skills of the students to apply the office software for the report designing.

The application of the web pages by the students reveals that the students have been less introduced to the digital library on campus. The university has provided the e-library for the online activities that it was supposed that the students use the system to surf, search, and download the materials for the study activities in the lockdown times. However, the traces to demonstrate a strong connection between the e-library and the students reports particularly in the research part was so poor. Nonetheless, the exercise take the place in the first year of study in the department and some of the gaps perhaps are related to the fresh students who arrived in the department in the COVID-19 times where many of the activities have been unstable. Therefore, some of the gaps in the production, presentation, and communication of the students are inevitable where both staff and students are learning to handle the tasks in the social distance condition.

\section{DISCUSSION}

Blended learning in the department was designed based on the activities and courses than program and institution as was argued by (Graham, 2009). In this structure was supposed that the activities arranged on the theoretical and online courses than practical project based activity. Despite the course presented based on a mixture of online, on campus, and on site activities, the facilities to handle the activities were limited due to internet connection and free online sources. However, the course was presented in both online and physical activities that recommended by the researchers such as (De George Walker \& Keeffe, 2010; Delialioglu \& Yildirim, 2007; Gülbahar 
\& Madran, 2009; McGee \& Reis, 2012). The site visiting activity supported the theory of physical activities in BL mode which was advocated by (Muñoz-Cristóbal et al., 2012).

The blended learning was applied in the course in terms of method of the instruction and methods that were discussed by (Medina, 2018). In fact, it was supposed that the instructor designs the instruction for BL mode learning to shift some physical classroom to online classrooms. Despite the transformation of the course to BL in term of the instruction and methods, the modality did not achieve results due to the fixed timetable in the institution. Flexibility was recommended (Owston et al., 2013) in the times and learning process in the BL mode that a fixed timetable and cleanroom activity reduced predicable resultants. Nonetheless, the site visiting, photography, sketching, analysis, and reporting were arranged based on more flexible time periods to support the students in both physical and theoretical activities that were inseparable.

The outputs of the students in the project-based activities were more accurate, database, and personal production based on the site visiting and analysis outputs due to the teamwork activities. The students supported each other not only the member of the group but also the classmates to tackle the unexpected problems in the activities. The results of the BL approved the theory of Sutton (Hewitt, 2003; Sutton, 2001) in terms of enhancement of the relationship between the students. Seemingly, this intended supportive system between the students was resultants of the context of the activity which was discussed in terms of socialization of the students (Dziuban et al., 2004). The results of the research confirmed effectiveness of the engagement the students in the physical and practical activities to lead them for sufficient planning, organizing the activities, and time management of the tasks that were mentioned by (Medina, 2010; Palmer \& Holt, 2014).

\section{CONCLUSION}

Blended learning is still a topic discussion, test, and experience by different instructors, programs, and institutions to adapt to the context of the study. Despite a lot of studies on BL achievements, the application of BL is depended on the instructor, course, department, and institution how to deliver educational materials through policy, strategy, action and infrastructure. Particularly, online capacity, facility and accessibility of the students to multiplatform online sources are crucial delivering courses. Limitation on the boundary of the internet, limitation to access the online sources, less flexibility of the timetable of the activities degrade the expected achievements from BL that all are dependent on institutional planning than activities of students and staff.

Despite the digital age is going to change the lifestyle broadly in the world, seemingly, architecture courses, programs, and instructors still are struggling to shift the orientation from the traditional style of teaching in the design studio with a face to face mode to BL mode. The curriculum of architecture programs has designed based on a traditional education based on the full attendance of the students in an apprenticeship discipline. However, BL is designed based on the flexibility of times and activities in the course that major part of the activities is designed by the learner than the instructor. Therefore, some traditional activities such as desk critics on the activities, pin-up of design products, and criticizing the deliverable do not take the place in BL and the departments, instructors, and institutions need to reorient their own educational perspectives.

The students learn differently in both theoretical and practical activities. The teamwork activities support the students to harmonize their own perspectives about the tasks and exercise outputs. The students present their personal understanding of the learning activities through exercises and project products. Both online and on site activities of the students enhance the level of the learning of the students. However, the students personalize the process of learning through interaction with the educational materials, instructions, and peer group members. The interactions between the education factors lead the students to personalization and specialization in the course. Nonetheless, both the quality and quantity of the productions of the students are different based on the resultants of educational factors. 
Despite blended learning makes the students far from the classrooms, seemingly, it makes close the students together for the practical activities. The results of the research reveal that teamwork activities enhance the interaction, communication, and support system of the students in the process of the delivery of the course. The students need an effective mentorship to apply selflearning, self-planning, and self-activities in the BL mode particularly in the first year of study based on the systematic handouts, instructions, and guidelines. This achievement points out that BL not only was included learning outcomes for the students in terms of the cognitive aspect of the learning but also it positively affects the attitudes of the students to help each other in the activities and the students improve the non-cognitive skills in BL mode gradually.

\section{REFERENCES}

Allen, I. E., Seaman, J., \& Garrett, R. (2011). Blending in: The Extent and Promise of Blended Education in the United States. In The Sloan Consortium. The Sloan Consortium. https://doi.org/10.1007/s00170-005-0274-8

Aycock, A., Garnham, C., \& Kaleta, R. (2002). Lessons Learned from the Hybrid Course Project. Teaching with Technology Today, 8(6), 9-21.

Bonnes, M., \& Bonaiuto, M. (2002). Environmental Psychology: from Spatial-Physical Environment to Sustainable Development. In Bechtel \& Churchman (Eds.), Handbook of Environmental Psychology. New York: John Wiley \& Sons.

Chen, C. C., \& Jones, K. T. (2007). Blended-Learning vs. Traditional Classroom Settings: Analyzing Students' Satisfaction with Inputs and Learning Processes in an MBA Accounting Course. In B. N. Schwartz \& A. H. Catanach (Eds.), Advances in Accounting Education: Teaching and Curriculum Innovations (Vol. 8). Advances in Accounting Education Vol. 8. Teaching and curriculum innovations. https://doi.org/10.1016/S1085-4622(07)08002-9

Cohen, L., Manion, L., \& Morrison, K. (2017). Research Methods in Education. In Research Methods in Education. Routledge. https://doi.org/10.4324/9781315456539

De George Walker, L., \& Keeffe, M. (2010). Self-Determined Blended Learning: A Case Study of Blended Learning Design. Higher Education Research \& Development, 29(1), 1-13. https://doi.org/10.1080/07294360903277380

Delialioglu, O., \& Yildirim, Z. (2007). Students' Perceptions on Effective Dimensions of Interactive Learning in a Blended Learning Environment. Educational Technology \& Society, $10(2), 133-146$.

Dziuban, C. D., Hartman, L. J., \& Moskal, P. (2004). Blended Learning. Educause Center for Applied Research. Research Bulletin, 7, 1-12.

Garrison, D. R., \& Kanuka, H. (2004). Blended Learning: Uncovering its Transformative Potential in Higher Education. The Internet and Higher Education, 7(2), 95-105. https://doi.org/10.1016/j.iheduc.2004.02.001

Gibson, D., Broadley, T., \& Downie, J. (2016). Blended Learning in a Converged Model of University Transformation. In Blended Learning for Quality Higher Education: Selected Case Studies on Implementation from Asia-Pacific. Blended learning for quality higher education: Selected case studies on implementation from Asia Pacific.

Gomez, L. A., \& Duart, J. M. (2011). A Hybrid Approach to University Subject Learning Activities. British Journal of Educational Technology, 42(2).

Graham, C. R. (2009). Blended Learning Models. In M. Khosrow-Pour (Ed.), Encyclopedia of Information Science and Technology, Second Edition. Hershey, PA: IGI Global. https://doi.org/10.4018/978-1-60566-026-4.ch063

Graham, C. R., \& Robison, R. (2007). Realizing the Transformational Potential of Blended Learning: Comparing Cases of Transforming Blends and Enhancing Blends in Higher Education. In A. G. Picciano \& C. D. Dziuban (Eds.), Blended Learning: Research Perspectives. Needham, MA: The Sloan Consortium.

Graham, C. R., Woodfield, W., \& Harrison, J. B. (2013). A framework for institutional adoption 
and implementation of blended learning in higher education. Internet and Higher Education. https://doi.org/10.1016/j.iheduc.2012.09.003

Groat, L., \& Wang, D. (2002). Architectural Research Methods. New York: John Wiley \& Sons INC.

Gülbahar, Y., \& Madran, R. O. (2009). Communication and Collaboration, Satisfaction, Equity, and Autonomy in Blended Learning Environments: A case from Turkey. International Review of Research in Open and Distance Learning, 10(2).

Hemyari, C., Zomorodian, K., Ahrari, I., Tavana, S., Parva, M., Pakshir, K., \& Sahraian, A. (2013). The Mutual Impact of Personality Traits on Seating Preference and Educational Achievement. European Journal of Psychological Education, 28, 863-877.

Hewitt, J. (2003). How Habitual Online Practices Affect the Development of Asynchronous Discussion Threads. Journal of Educational Computing, 28(1), 31-45. https://doi.org/10.2190/PMG8-A05J-CUH1-DK14

Krippendorff, K. H. (2003). Content Analysis: An Introduction to its Methodology (2nd ed.). New York: Sage Publications.

Lane, M., Osborne, L., \& Crowther, P. (2015). A Blended Learning Approach to the Teaching of Professional Practice in Architecture. Educ. Sci, 5, 166-178. https://doi.org/10.3390/educsci5020166

Lawson, B. (2005). How Designers Think: the Design Process Demystified (4th ed.). Oxford Press.

Martin, M. H. (2003). Factors Influencing Faculty Adoption of Web-based Courses in Teacher Education Programs within the State University of New York. Doctoral Dissertation.

McGee, P., \& Reis, A. (2012). Blended Course Design: A Synthesis of Best Practices. Journal of Asynchronous Learning Networks, 16(4), 7-22.

Medina, C. L. (2010). Metacognitive Instructional Strategies: A Study of E-learners' Selfregulation. Fourteenth International Conference of Motivation and Beyond.

Medina, L. C. (2018). Blended Learning: Deficits and Prospects in Higher Education. Journal of Educational Technology, 34(1), 42-56.

Moore, N., \& Gilmartin, M. (2010). Teaching for Better Learning: A Blended Learning Pilot Project with First-year Geography Undergraduates. Journal of Geography in Higher Education, 34(3), 327-344. https://doi.org/doi:10.1080/03098265.2010.501552

Mugerauer, R. (1995). Interpreting Environments: Tradition, deconstruction, Hermeneutics. University of Texas.

Muñoz-Cristóbal, J. A., Prieto, L. P., Asensio-Pérez, J. I., \& Jorrín-Abellán, I. M Dimitriadis, Y. (2012). Lost in Translation from Abstract Learning Design to ICT Implementation: A Study using Moodle for CSCL. In 21st Century Learning for 21st Century skills, 7th European Conference on Technology Enhanced Learning, EC-TEL2012.

Neuman, L. W. (2006). Social Research Methods: Qualitative and Quantitative Approaches. New York: Pearson Education.

O' Sullivan, M. (2006). What Do We Know about the Professional Preparation of Teachers? In C. Silverman, S. \& Ennis (Ed.), Student Learning in Physical Education: Applying Research to Enhance Instruction (pp. 315-337). Human Kinetics.

Owston, R., York, D., \& Murtha, S. (2013). Student Perceptions and Achievement in a University Blended Learning Strategic Initiative. Internet and Higher Education, 18, 38-46. https://doi.org/10.1016/j.iheduc.2012.12.003

Palmer, S., \& Holt, D. (2014). Development of Student and Academic Staff Perceptions of the Elements of an Online Learning Environment Over Time. Australasian Journal of Educational Technology, 30(4), 375-389. https://doi.org/10.14742/ajet.581

Picciano, A. G. (2009). Blending with Purpose: the Multimodal Model. Journal of the Research Center for Educational Technology, 5(1), 4-14.

Piper, T. (2010). What Policy Changes do Experts Recommend K-12 Instructional Leaders Enact to Support the Implementation of Online Instruction and Learning? In Pro Quest 
Dissertations and Theses.

Powell, A. (2011). A Case Study of E-learning Initiatives in New Zealand's Secondary Schools.

Prieto, L. P., Muñoz-Cristóbal, J. A., Asensio-Pérez, J. I., \& Dimitriadis, Y. (2012). Making Learning Designs Happen in Distributed Learning Environments with GLUE!-PS. In 21st Century Learning for 21st Century skills, 7th European Conference on Technology Enhanced Learning, EC-TEL2012.

Rossett, A. (2002). The ASTD E-Learning Handbook: Best Practices, Strategies, and Case Studies for an Emerging Field.

Schon, D. A. (1984). The Architectural Studio as an Exemplar of Education for Reflection-inAction. Journal of Architecture Education, 38, 2-9.

Shulman, L. S. (2005). Signature Pedagogies in the Professions. Daedalus, 134, 52-59.

Silverman, D. (2004). Qualitative Research: Theory, Method and Practice. SAGE Publications Ltd.

Sutton, L. A. (2001). The Principle of Vicarious Interaction in Computer-Mediated Communications. International Journal of Educational Telecommunications, 7(3), 223-242.

Tafahomi, R. (2020). Educational Outcome of Students' Group-Table Arrangement for Collaboration in Architectural Thesis Studio. LWATI: A Journal of Contemporary Research, $17(2), 22-46$.

Tafahomi, R. (2021a). Application of Physical and Nonphysical Elements in the Conservation of Historic Core of City. South African Journal of Geomatics, 10(1), 75-86. https://doi.org/10.4314/sajg.v10i1.6

Tafahomi, R. (2021b). Qualities of the Green Landscape in Primary Schools, Deficiencies and Opportunities for Health of the Pupils. J. Fundam. Appl . Sci, 13(2), 1093-1116. https://doi.org/10.43 14/jfas.v13i2.25

Tafahomi, R., \& Nadi, R. (2020). Insight Into the Missing Aspects of Therapeutic Landscape in Psychological Centers in Kigali, Rwanda. Cities \& Health, Online, 1-13. https://doi.org/10.1080/23748834.2020.1774035

Williams, M., \& Robert, L. B. (1997). Psychology for Language Teachers. Cambridge University Press.

Woolfolk, A. (2016). Educational Psychology. Boston: Pearson.

Woollard, J. (2010). Psychology of Classroom: Behaivouralism. 